\title{
Disorders of Consciousness: Practical Management in an Emergency Room
}

\section{Distúrbios da consciência: Abordagem prática na sala de emergência}

\author{
Daniel Damiani ${ }^{1 \odot}$ \\ ${ }^{1}$ Department of Neuroscience, Universidade Anhembi Morumbi, \\ São Paulo, SP, Brazil \\ Arq Bras Neurocir 2019;38:263-271
}

\begin{abstract}
Address for correspondence Daniel Damiani, MD, Department of Neuroscience, Universidade Anhembi Morumbi, Sao Paulo, SP 04705000, Brazil (e-mail: damiani.neuroscience@gmail.com).
\end{abstract}
Abstract
Keywords
- coma - coma in emergency
room
- reversible causes of coma
- ascending reticular activating system
- consciousness and coma
- brainstem

Lowering of the level of consciousness is a very common presentation at the emergency room, often without any history that helps finding an etiology. This emergency requires quick empirical measures to reduce neuronal mortality, with additional protection against sequelae. According to the Advanced Cardiac Life Support (ACLS) guidelines, there are current emergency neurological support protocols, such as the Emergency Neurological Life Support (ENLS) created by the Neurocritical Care Society. The present paper shows how to approach unconscious patients, highlighting possible etiologies and proposed treatments.

\section{Resumo}

Palavras-chave

- coma

- coma na sala de emergência

- causas reversíveis de coma

- sistema reticular ativador ascendente

- consciência e coma

- tronco encefálico
O rebaixamento do nível de consciência é uma situação frequente na sala de emergência, muitas vezes sem qualquer história prévia que auxilie no esclarecimento etiológico. Trata-se de uma situação de emergência que exige medidas empíricas imediatas no intuito de reduzir a mortalidade neuronal com proteção adicional à zona de penumbra. A exemplo do preconizado pelo Suporte Avançado da Vida Cardiovascular (SAVC), atualmente estão disponíveis os protocolos de suporte neurológico de emergência (ENLS, na sigla em inglês) preconizados pela Neurocritical Care Society. $O$ presente artigo apresenta os princípios gerais no manejo inicial do paciente com rebaixamento do nível de consciência, destacando as suas possíveis etiologias e seus tratamentos propostos.

\section{Introduction}

Coma is an unconsciousness state defined by the inability to respond to external stimuli, in which the patient remains unaware, ignorant of the self and of other people. Didactically, consciousness has two components: the level and the content of consciousness. The level of consciousness (also referred as arousal) reflects the most primordial central nervous system (CNS) structures belonging to the reptilian brain from the MacLean model, represented by the brainstem and by the
Copyright $\odot 2020$ by Thieme Revinter Publicações Ltda, Rio de Janeiro, Brazil
License terms

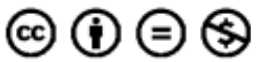

received

June 8, 2016

accepted

July 27, 2016

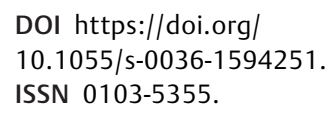


diencephalic structures (the thalamus and the hypothalamus), collectively referred to as the ascending reticular activating system (ARAS). The content of consciousness concerns higher cortical functions, such as gnosis, praxis, memory, learning, reasoning, and orientation in time and space, and it is represented by the neocortex. Therefore, coma represents the involvement of the brainstem and/or of any diencephalic structure, which are primordial for maintaining arousal. ${ }^{1-3}$ Variations of the classic coma are described and collectively referred to as disorders of consciousness: minimally conscious state, vegetative state, hypersomnia, abulia, and akinetic mutism. The minimally conscious state is characterized by content impairment and unconsciousness, with some preservation of awareness of the self and of the environment. The vegetative state occurs when the comatose patient presents sleep-wake cycles, with autonomic control (including respiratory drive), and spontaneous ocular opening, but deep unconsciousness of the self and of the environment. These two situations refer to bilateral cortical lesions or to extensive lesions affecting the cortical connectivity. Hypersomnia consists in excessive sleepiness or fatigue during the day, and is primarily idiopathic or results from structural or metabolic changes. Abulia is a decrease in initiative along with apathy; it can occur after frontal lobe damage, and it may evolve with akinetic mutism. ${ }^{4-8}$ In the clinical practice, many patients arrive at the emergency room with a lower level of consciousness: the patient may be disoriented, sleepy, obtunded (sleepy and disoriented), apathic, or already comatose. Since there are many possible causes for this clinical picture, the clinical history and a proper physical examination are fundamental to establish an etiological diagnosis. The physician should be aware of possible acute causes that require emergency procedures to reduce their morbidity and mortality. ${ }^{1}$ Huff et al recommend an algorithm for the management of comatose patients in the emergency room based on the conventional algorithms Advanced Cardiac Life Support (ACLS) and Advanced Trauma Life Support (ATLS), called Emergency Neurological Life Support (ENLS). This algorithm, like the traditional ATLS and ACLS protocols, guides emergency professionals and intensivists on the critical measures to be adopted as priorities for the treatment of patients with acute neurological injury. ${ }^{2,9}$

\section{Objectives}

The author describes the current knowledge on the physiology of the level and content of consciousness, as well as the pathophysiology of unconsciousness, including coma, highlighting its major etiological factors, both acute and reversible at the first emergency room visit, following an emergency approach protocol to acute neurological injuries.

\section{Methodology}

A quantitative and descriptive research was performed per a narrative literature review in the Latin American and Caribbean Literature in Health Sciences (LILACS) and in the National Library of Medicine (PubMed) databases in May, 2016, using the following descriptors: coma, emergency room, intensive care, consciousness, brainstem, and ascending reticular system. The following combinations were used in the search: coma in emergency room, reversible causes of coma, consciousness and coma, and ascending reticular system and brainstem.

The present study asks the following question: how to correctly manage the patient in a coma at the emergency room?

The inclusion criteria for papers were updated publications from the period between 2001 and 2016, with rare exceptions, in Portuguese and English, and with online access to the full text. As exclusion criteria, in addition to papers that did not comply with the inclusion criteria, duplicate papers were eliminated.

For the analysis of the papers included in the present review, the following aspects were observed: year of publication, journal, place of study, methodology used, and main results.

\section{Development}

Pathophysiology of the lowering of the level of consciousness. Consciousness is a complex of neuronal interconnections involving cortical, subcortical, and deep nuclei areas, influenced by inhibitory and excitatory neurotransmitters. The ARAS, located in the brainstem, is responsible for the maintenance of the level of consciousness, and it consists of several nuclei in the brainstem, in the thalamus, and in the hypothalamus. The content of consciousness is represented by the cerebral cortex, as already mentioned. Moruzzi et al, in 1949, were the first to describe the ARAS, using experimental brainstem transections in cats. After midbrain lesions, the animals were unable to maintain their level of consciousness, becoming comatose (-Fig. 1). ${ }^{10}$

Brainstem. The structures related to the maintenance of the level of consciousness are the raphe nuclei, the locus coeruleus, the reticular formation, the pars compacta of the substantia nigra, the ventral tegmental area, and the mesopontine tegmentum, which includes the tegmental pedunculopontine nucleus and the laterodorsal tegmental nucleus. The dendrites of these neurons form true integrative networks between the afferent and efferent synaptic outflow. Unsynchronized discharges to the cerebral cortex, alternating low and high amplitudes, are responsible for maintaining the level of consciousness with the possible expression of its content. Physiologically, when the structures of the brainstem, of the hypothalamus, and of the thalamus synchronize their electrical discharges to the cortex, with slow waves of higher amplitude, the level of consciousness is reduced. ${ }^{11,12}$ The cholinergic system acts at the entire cerebral cortex both during wakefulness and rapid eye movement (REM) sleep. These neurons stimulate directly the cerebral cortex and inhibit the reticular nucleus of the thalamus (responsible for slow-wave sleep induction), leading to a desynchronization of the cortical waves. Cholinergic activity, in turn, promotes cortical activation by stimulating glutamatergic, noradrenergic, serotonergic, and histaminergic neurons present in the ARAS structures. Gamma-aminobutyric acid (GABA)ergic neurons also 


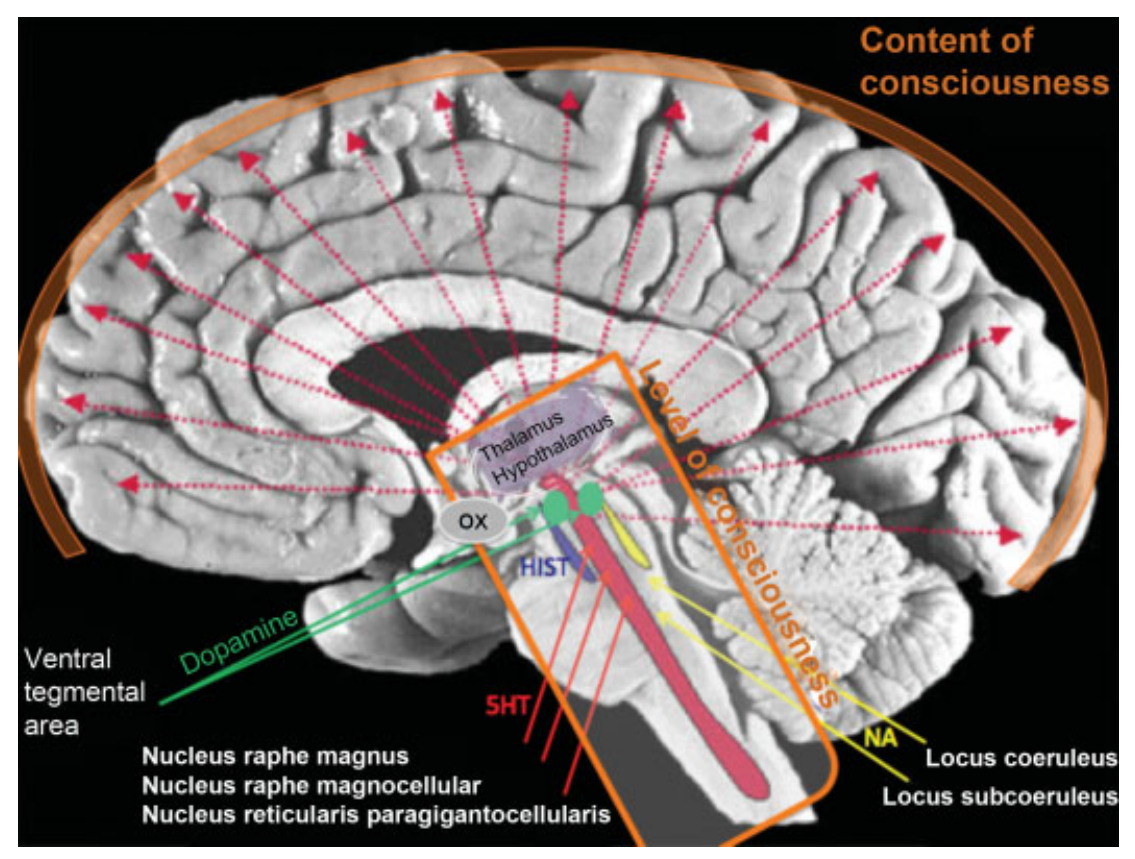

Fig. 1 Structures responsible for the content and level of consciousness. The content of consciousness requires the functioning of the cerebral cortex, which cannot generate the level of consciousness. The latter depends on subcortical structures, such as the hypothalamus and the thalamus, as well as the brainstem. Abbreviations: 5HT, 5-hydroxytryptamine (serotonin); HIST, histamine (arising from the tuberomammillary nucleus); NA, norepinephrine; OX, orexin (present in the hypothalamic periventricular nucleus).

project themselves together with cholinergic fibers through thalamic irradiation, promoting ascending disinhibition and neuronal activation. Lesions in the ventral tegmental areas and in the substantia nigra present with akinesia with no impairment of the cortical activation. ${ }^{11}$

Posterior Hypothalamus. This heterogeneous region, composed of histaminergic, dopaminergic, glutamatergic, and GABAergic neurons, is associated with neuropeptides such as orexin, enkephalin and substance $P$, and it has a great influence on the wakefulness process. During the influenza epidemic in 1918, Von Economo ${ }^{11}$ described lesions in the posterior and in the anterior hypothalamus, respectively, associated with hypersomnia (including drowsiness and coma), and insomnia. Recently, a hypothalamic-cortical projection system, deemed responsible for maintaining the level of consciousness, has been described. Histamine and the neuropeptide orexin have great relevance in this arousal-activating mechanism. Histamine acts on its $\mathrm{H} 1$ receptor, activating the $\mathrm{Gq} / 11$ protein, causing depolarization with sodium and calcium influx; on its $\mathrm{H} 2$ receptor, $\beta$-adrenergic receptor and 5HT2, it activates Gs protein (adenylate cyclase-coupled), increasing the expression of the CAMP response element binding protein (CREB) transcription factor; and on its $\mathrm{H} 3$ receptor (a self-receptor coupled to a Gq protein and to high-voltage calcium channels), it is responsible for the negative feedback to the production and release of histamine itself ( - Fig. 1). The excitatory neurotransmitter for orexinergic neurons is glutamate, and their inhibitory neurotransmitter is dynorphin. ${ }^{11-14}$

Some CNS lesions may compromise the structures responsible for the maintenance of arousal, such as traumatic brain injury (TBI), intracranial hemorrhage (ICH), subarachnoid hemorrhage (SAH), ischemic stroke, and global hypoxicischemic brain injury. In ICH, arousal is often preserved at the beginning of the clinical picture; however, as the hematoma expands, the level of consciousness is impaired. If the origin of the ICH affects the infratentorial space, the risk of impaired consciousness is higher, due to anatomical reasons. In the supratentorial space, the bleeding affecting the medial thalamic nuclei often results in unconsciousness. Lobar lesions that deviate the midline will compromise the level of consciousness by compression of thalamic nuclei, of the brainstem, and/or of thalamic projection structures. In SAH, either traumatic or spontaneous, the intracranial pressure increases abruptly, whereas the cerebral perfusion pressure is reflexively reduced, resulting in swelling, transient ischemia, and cytotoxic edema. Subarachnoid hemorrhage can indirectly damage the hypothalamus. Indirect hypothalamic lesions (due to increased intracranial pressure and/or to vascular lesions) reduce orexin (hypocretin) levels, resulting in unconsciousness. It is not uncommon for SAH survivors to present changes in the wake-sleep cycle, including excessive daytime fatigue. In ischemic stroke, unconsciousness is not common, except in cases involving correlated structures. The decreased level of consciousness results from cerebral edema with midline deviation due to already mentioned factors. A malignant infarction of the middle cerebral artery classically presents with a major cerebral edema; decompressive craniectomy is commonly indicated, reducing its mortality by up to $50 \%{ }^{1}$ Lastly, the global hypoxicischemic brain injury is due to brain hypoperfusion, often following prolonged cardiorespiratory arrest. Neuronal damage starts within 2 minutes of cerebral blood hypoperfusion. Some structures 
are more sensitive to hypoxia: the hippocampus (CA1 and CA4 regions); pyramidal cells from layers 3, 5 and 6; the amygdaloid complex; the cerebellar worm; the caudate nucleus; and the brainstem nuclei. The reticular nucleus, the intralaminar nuclei of the thalamus, and the medial geniculate nucleus are particularly sensitive to ischemia. The return of the spontaneous circulation causes reperfusion injury. Several components of the anaerobic metabolism may damage neurons, including free radicals, extracellular glutamate causing excitotoxicity by calcium influx, changes in glial morphology, and astrocytic activation by increased levels of proinflammatory interleukins and tissue necrosis factor $\alpha{ }^{4,15,16}$

Reversible causes of lowered level of consciousness. There are innumerable possible causes of lowered level of consciousness, and some of them can be immediately reversed with emergency intervention. As already mentioned, the three major mechanisms responsible for disorders of the level of consciousness are: structural brain lesions, diffuse neuronal dysfunctions (resulting from various metabolic conditions that may compromise neuronal function), and, rarely, psychiatric causes. Except for the latter, the other mechanisms will somehow involve the ARAS and its connections, the diencephalic structures (the hypothalamus and/or the thalamus) and/or the cerebral cortex (-Table 1). After immediate clinical stabilization, which will be described later, the emergency physician or intensivist should consider the reversible causes of coma and actively try, even if initially empirically, to reduce the neurological damage.

Clinical management in the emergency room. The proposed creation of an algorithm for the management of the critical neurological patient in the emergency room follows the model of the traditional algorithms of the American Heart Association, namely ATLS and ACLS. It is a sequence of emergency measures for rapid diagnosis and prompt therapy, minimizing secondary neurological lesions. The $1^{\text {st }} 60$ minutes are critical for the neurological patient, and there are rare times when a neurologist and/or neurosurgeon are available in the emergency department within that time frame. In this context, the Neurocritical Care Society develops algorithms for the care of critical neurological patients. $^{17}$

The neurological examination is the $1^{\text {st }}$ step in evaluating patient with a lowered level of consciousness in the emergency room. The Glasgow coma scale was described in 1974 , and it has been widely used in these situations. ${ }^{18}$ In 2005 , however, a scale called Full Outline of UnResponsiveness (FOUR) was published to better evaluate intubated patients, and it includes an evaluation of brainstem reflexes, not considered by the Glasgow scale (-Fig. 2 ). The examination of the motor and ocular functions indicates the neurological prognosis; the ocular examination seems to have a better predictive value compared with the motor examination. The absence of pupillary reflexes following cardiorespiratory arrest, for example, represents a very poor prognosis. Oculovestibular and oculocephalic reflexes also have prognostic values. The electroencephalogram (EEG) value was also studied and associated with the prognosis for neurological damage: the presence of periodic and/or generalized epileptiform discharges, generalized suppression patterns, lack of activity, or even the presence of alpha and theta waves in coma represent a worse prognosis. Somatosensory evoked potentials (SSEP) with identification of cortical N20 response after median nerve stimulation were studied: the absence of the $\mathrm{N} 20$ response represents a higher mortality, while a slow $\mathrm{N} 20$ response is associated with a persistent vegetative state and brain death. It is, therefore, a good predictor of coma prognosis; however, there are some disadvantages, including the need for specialized professionals to perform and interpret the test; electrical interference; and the required exclusion of subcortical, medullary and/or peripheral lesions that may affect cortical response. Biomarkers of neural glial lesions are now available, including a neuron-specific enolase and $\mathrm{S} 100 \mathrm{~B}$ protein. In diffuse axonal lesions, the elevated levels of these markers in 72 hours are predictors of a worse prognosis.

\section{Proposed Algorithm for Comatose Patient Approach: Emergency Neurological Life Support}

In emergency medicine, the patient is classified as comatose when he presents closed eyes, preserved reflexes, and reduced or absent response to external stimuli (-Fig. 3). The level of responsiveness, as well as its response pattern, is assessed by the examiner and graded by the Glasgow coma scale and by the FOUR scale. ${ }^{19}$ Verbal and tactile-painful stimuli are performed to elicit the response of the patient. The attempt to open the eyelids of the patient is a simple and effective test; the arm drop test on the face is often used. The recommended protocol for these patients includes the initial stages of ACLS and ATLS resuscitation (cervical stability, airway viability), the assessment of respiratory rate, oxygen saturation, heart rate, and blood pressure, the establishment of one or two large-bore venous access to immediately draw blood samples for serum biochemistry analysis, blood sugar level, toxicology (including alcohol), coagulation profile, electrolytes (mainly sodium and calcium), arterial blood gases, urine and cultures. ${ }^{1}$ If an orotracheal intubation (OT) is required, it should be performed with adequate analgesia, sedation, and neuromuscular paralysis (when indicated). There are four classic indications for OT in neurological lesions: (1) respiratory failure confirmed by oximetry (with caution regarding methodological limitations), arterial blood gas analysis and/or cyanosis; (2) inability to ensure a safe airway (absence of protective reflexes); (3) severe clinical injury with cardiopulmonary function compromise; (4) failure of noninvasive methods, such as catheters, masks, and noninvasive ventilation (NIV). Ideally, a rapid and objective neurological examination should be performed prior to the administration of sedative, hypnotic, and/or neuromuscular paralytic agents. The level and content of consciousness, the function of the cranial nerves, motor limb activity, deep osteotendinous tonus and reflexes, convulsive activity, cervical stability, and sensory level 
Table 1 Some brain lesions caused by mass effect and classified as structural versus diffuse neuronal lesions

\begin{tabular}{|c|c|c|}
\hline Structural brain injury & Usual treatment & Comments \\
\hline Brain tumor, mass effect & Neurosurgery and corticosteroids & Intracranial pressure reduction \\
\hline Status epilepticus & Anticonvulsive drugs & $\begin{array}{l}\text { Sedation and induced coma may be } \\
\text { required }\end{array}$ \\
\hline $\begin{array}{l}\text { Central nervous system infections, } \\
\text { sepsis }\end{array}$ & $\begin{array}{l}\text { Antibiotics, steroids and abscesses } \\
\text { drainage }\end{array}$ & Immediate empirical treatment \\
\hline Intracranial hypertension & $\begin{array}{l}\text { Elevate head bed, hyperosmolar } \\
\text { solution, hyperventilation, corticoids }\end{array}$ & $\begin{array}{l}\text { Intracranial pressure monitoring should } \\
\text { be considered }\end{array}$ \\
\hline Subdural and extradural hematoma & Neurosurgical drainage & Multimodal monitoring \\
\hline Intracranial hemorrhage & $\begin{array}{l}\text { Neurosurgical hemostatic therapy, } \\
\text { drainage, blood pressure control }\end{array}$ & $\begin{array}{l}\text { Clinical and vascular research: } \\
\text { angiography }\end{array}$ \\
\hline Ischemic stroke & Thrombolytic therapy & Clinical and vascular research \\
\hline Hydrocephalus & Ventriculostomy with drainage & $\begin{array}{l}\text { Acetazolamide: inhibitor of } \\
\text { cerebrospinal fluid production }\end{array}$ \\
\hline Brain edema & Decompressive craniectomy & On a per case basis \\
\hline Cerebral venous thrombosis & Anticoagulants & $\begin{array}{l}\text { Etiologic search: contraceptive use, } \\
\text { Leiden factor } \mathrm{V} \text { mutation, prothrombin } \\
\text { gene mutation, immune and } \\
\text { rheumatologic markers }\end{array}$ \\
\hline Diffuse neuronal lesions & Usual treatment & Comments \\
\hline Hypoglycemia & Hypertonic glucose 50\%, intravenously & Clinical emergency! \\
\hline Hyperglycemia, DKA, HHS & Hydration and insulin therapy & Search for precipitating factor \\
\hline Hyponatremia & $\begin{array}{l}\text { Sodium replacement: always with } 3 \% \\
\mathrm{NaCl}: 3 \mathrm{mEq} / 3 \mathrm{~h}+9 \mathrm{mEq} / 21 \mathrm{~h}\end{array}$ & Investigate other electrolytes \\
\hline Hypercalcemia & $\begin{array}{l}\text { Hydration, furosemide, intravenous } \\
\text { bisphosphonates, calcitonin, dialysis }\end{array}$ & $\begin{array}{l}\text { Investigate precipitating causes: PTH, } \\
\text { paraneoplastic syndrome, lymphoma }\end{array}$ \\
\hline Renal failure & Dialysis & Investigate cause \\
\hline Hyperammonemia & According to etiology & $\begin{array}{l}\text { Hepatic failure: high lactate level, } \\
\text { hypoglycemia, coagulopathy }\end{array}$ \\
\hline $\begin{array}{l}\text { Hepatic failure, } \\
\text { hepatic encephalopathy }\end{array}$ & $\begin{array}{l}\text { Lactulose, mannitol, vitamin K or FFP, } \\
\text { prophylactic antibiotic therapy, } \\
\text { flumazenil }\end{array}$ & $\begin{array}{l}\text { Head CT: cerebral edema; protein } \\
\text { restriction: } 1.0-1.5 \mathrm{~g} / \mathrm{kg} / \text { day via NET }\end{array}$ \\
\hline Thyrotoxicosis & $\begin{array}{l}\text { Beta-blockers, PTU, inorganic iodine, } \\
\text { dexamethasone }\end{array}$ & Etiological investigation \\
\hline Myxedema coma & $\begin{array}{l}\text { Hormonal replacement: } \\
\text { levothyroxine + hydrocortisone }\end{array}$ & $\begin{array}{l}\text { Perform associated hydric and } \\
\text { electrolyte corrections and correct } \\
\text { hypothermia }\end{array}$ \\
\hline Hypocortisolism (Addisonian crisis) & Hydration + steroid therapy & \\
\hline Wernicke encephalopathy & Thiamin (vitamin B1) & $\begin{array}{l}\text { Associated with thiamine-free glucose } \\
\text { replacement in alcoholism }\end{array}$ \\
\hline Serotoninergic syndrome & Benzodiazepines & Consider neuromuscular paralysis \\
\hline Cholinergic poisoning & Atropine, pralidoxime & $\begin{array}{l}\text { Poisons, organophosphates, } \\
\text { carbamates }\end{array}$ \\
\hline Opioids & Naloxone & $\begin{array}{l}\text { Caused by morphine, heroin, } \\
\text { phenylethyl, tramadol }\end{array}$ \\
\hline Benzodiazepines & Flumazenil & $\begin{array}{l}\text { Suicide attempts with diazepam, } \\
\text { lorazepam, alprazolam }\end{array}$ \\
\hline
\end{tabular}

Abbreviations: DKA, diabetic ketoacidosis; HHS, hyperosmolar hyperglycemic state; FFC, fresh frozen plasma; PTH, parathyroid hormone; PTU, propylthiouracil; NET, nasoenteral tube. 


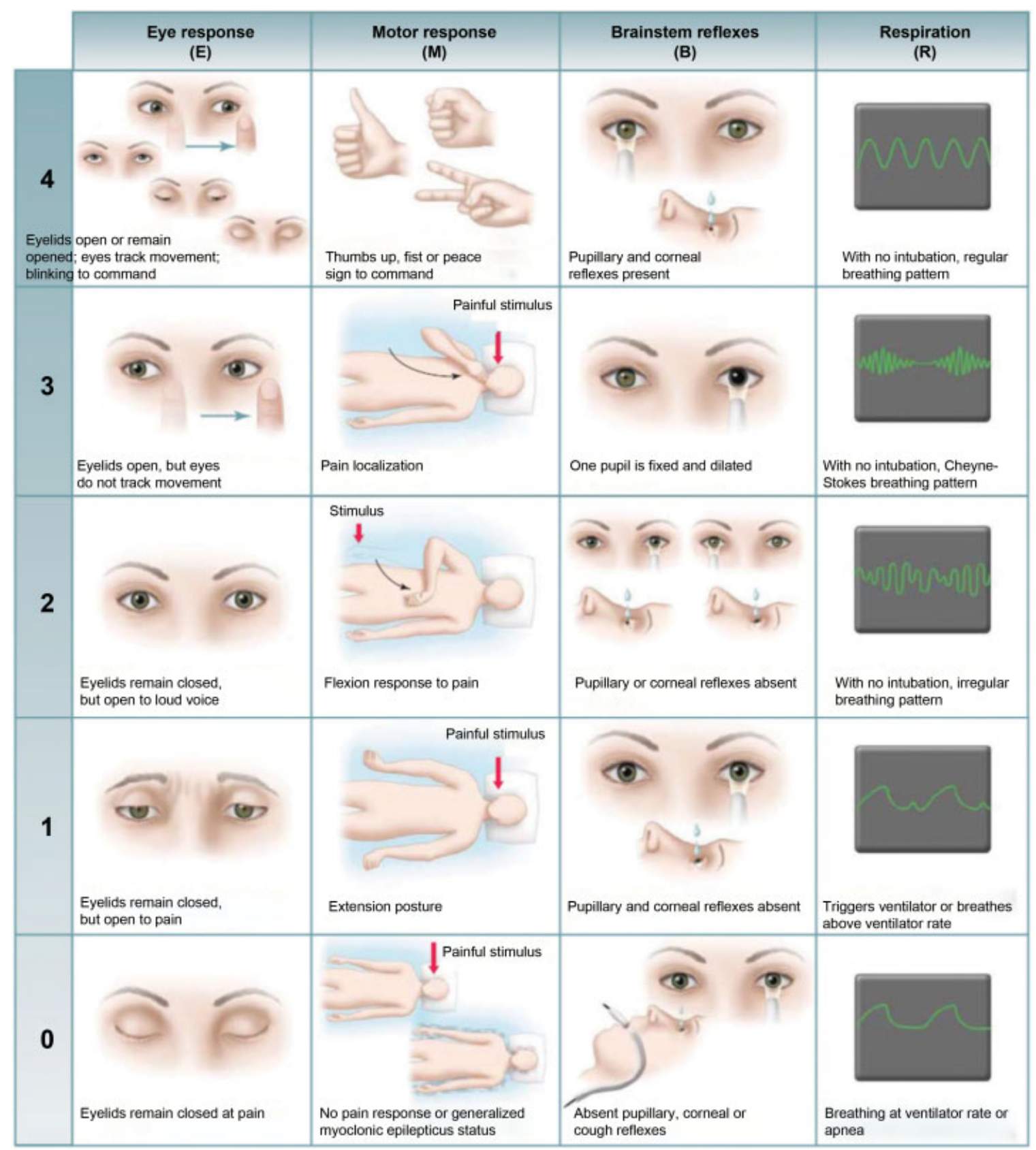

Fig. 2 FOUR (Full Outline of UnResponsiveness) coma scale.

should be evaluated in cases with suspicion of spinal cord injury. The rapid intubation sequence is the method of choice for cases with suspicion of intracranial hypertension, reducing the risk of its reflexive increase (mediated by the autonomic sympathetic nervous system) during laryngoscopy. The presence of coma is not an indication for the nonuse of hypnotic and analgesic agents. Even a comatose patient may present laryngoscopy reflexes that increase the intracranial pressure due to a higher neuroendocrine and immunological response. The mean arterial blood pressure (MAP) and the intracranial pressure (ICP) should be carefully controlled to maintain the cerebral perfusion pressure (CPP) between 60 and $70 \mathrm{~mm} \mathrm{Hg}$. $^{20,21}$

Three preintubation medications can prevent the increase of the ICP: lidocaine $(1.5 \mathrm{mg} / \mathrm{kg}$ intravenously [IV], adminis- tered 1 minute before OT); fentanyl $(2-3 \mu \mathrm{g} / \mathrm{kg}$ IV, administered 30 seconds to 1 minute prior to OT), but it must be avoided in hypotensive patients; and esmolol ( $1-2 \mathrm{mg} / \mathrm{kg}$ IV, 3 minutes before OT), which acts as a short-term $\beta$-blocker for heart rate and blood pressure control during OT, but which it is rarely used due to coexistent hypotension. The hypnotic agents recommended due to their little interference with ICP are etomidate $(0.2-0.4 \mathrm{mg} / \mathrm{kg}$ IV), which promotes sedation and neuromuscular relaxation without hemodynamic damage (this is the hypnotic of choice in cases with increased ICP); propofol (0.5-3.0 $\mathrm{mg} / \mathrm{kg}$ IV), despite its potent vasodilator effect; and thiopental ( $3 \mathrm{mg} / \mathrm{kg} \mathrm{IV}$ ), which is considered a brain protective agent for reducing the basal cerebral metabolic rate and the fraction of oxygen extraction by brain tissue, diminishing the ICP (however, it has a 


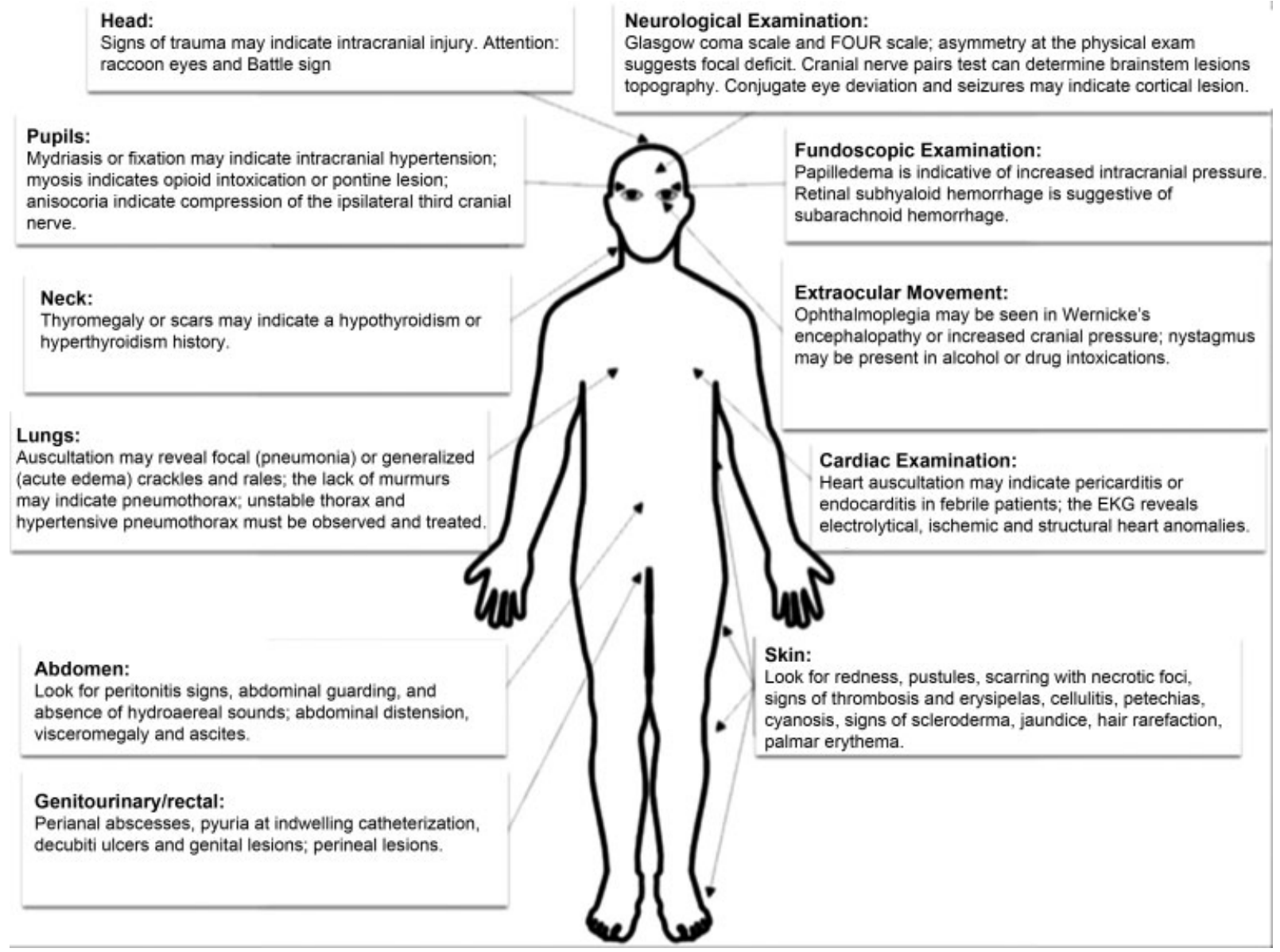

Fig. 3 Physical examination of the comatose patient in the emergency room. Modified from Han et al. ${ }^{27}$

negative inotropic effect and is a venous dilator with major hypotensive potential). Ketamine $(0.5-2.0 \mathrm{mg} / \mathrm{kg} \mathrm{IV})$ is also a good option in cases with increased ICP with little influence over the hemodynamic pattern. Succinylcholine (1.0-1.5 $\mathrm{mg} / \mathrm{kg} \mathrm{IV)}$ is the depolarizing neuromuscular blocking agent of choice in patients with elevated ICP. Even though there are reports of slight ICP increases, the very short halflife of succinylcholine does not appear to impair nerve cells. However, studies have shown that patients with brain injuries, spinal cord injuries, major atrophies, and prolonged immobility are more susceptible to succinylcholine-induced hyperkalemia. In such high-risk patients, the use of nondepolarizing neuromuscular blockers, such as rocuronium (0.5-0.6 mg/kg IV), and vecuronium ( $0.2 \mathrm{mg} / \mathrm{kg} \mathrm{IV})$, seems to be a good alternative. ${ }^{22-26}$

Immediately after the bedside determination of the capillary blood sugar level, if it is $<70 \mathrm{mg} / \mathrm{dL}, 40 \mathrm{~mL}$ of hypertonic glucose at $50 \%$ should be infused intravenously. If there is suspicion of alcohol intoxication or a history of use, malnutrition or a history of bariatric surgery, the emergency physician should administer $100 \mathrm{mg}$ of thiamine IV. The suspicion of opioid intoxication should be based on unconsciousness with bilateral miotic pupils, and the empirical IV administration of $0.4-2.0 \mathrm{mg}$ naloxone (with a maximum dose of $4 \mathrm{mg}$ ) is indicated. The "coma kit", including naloxone, atropine, flumazenil and thiamine, is not indicated without the proper assessment of the patient for clinical signs warranting its use. The electrocardiogram (EKG), performed on arrival, can provide indications about the cause of unconsciousness: electrolytic changes, ischemia, arrhythmias, and structural heart diseases can be diagnosed at this first ECG. At the neurological examination, asymmetry findings strongly suggest focal lesions, while symmetry suggests lesions due to metabolic causes. The neurological evaluation of the patient in coma should follow four steps: (1) level of consciousness (Glasgow coma scale and FOUR scale); (2) brainstem reflexes (oculocephalic and oculovestibular maneuvers, cranial pairs test with pupil evaluation); (3) motor assessment (spontaneous, reflexive, or induced by painful stimuli); (4) evaluation of the respiratory pattern, which is important to determine the topography of the lesion (a Cheyne-Stokes pattern suggests supratentorial lesions; neurogenic hyperventilation suggests mesencephalic lesions; apneustic pattern suggests pons lesions; ataxic breathing suggests medulla oblongata lesions). ${ }^{27}$

A brief clinical history may be obtained from family members, from bystanders, or from the prehospital care team. Some history features are strongly suggestive of the coma etiology: sudden onset (suggesting a vascular etiology, seizure, or drug overdose); tumor history (suggesting metastasis); hemorrhagic disorders (suggesting ICH, subdural hematoma, SAH); hypercoagulability states (suggesting dural sinus thrombosis); 
assisted seizures and gradual worsening to coma (suggesting tumoral or inflammatory diseases). ${ }^{27}$

At that time, neuroimaging is a fundamental part of the assessment: structural lesions are potentially treated with an early neurosurgical approach and should be diagnosed as soon as possible. A computed tomography (CT) scan of the skull without contrast medium is the test of choice due to of its great availability, low cost, and fast execution; however, it requires hemodynamic stability. Focal hypodensities suggestive of stroke, ICH, SAH, brain edemas, herniations, and acute hydrocephalus are readily diagnosed. In the infectious hypotheses, CT scans with and without contrast medium can be useful in the exclusion of cerebral abscess, of extra-axial collections, of hemorrhagic transformations, and of hydrocephalus, even before lumbar puncture. Comas due to nonstructural lesions include hypoxicischemic encephalopathy, sepsis, epilepsies, metabolic alterations, endocrinopathies, toxins, and drugs. More specific lesions - including white matter involvement, neoplasms, posterior fossa and brainstem lesions - are better investigated by more accurate methods, such as magnetic resonance imaging (MRI) of the brain, magnetic resonance angiography, and digital angiography. In the hyperacute phases of the ischemic stroke, a brain MRI with diffusion will be diagnostic, since the skull CT will not show lesions. ${ }^{1,2}$

In undetermined cases, a lumbar puncture may aid the diagnosis. Infections, inflammation, neoplasms, demyelinations, and autoimmune diseases can be diagnosed by a cerebrospinal fluid (CSF) analysis. If a status epilepticus is suspected, an EEG should be requested ${ }^{2}$ (-Fig. 4).

Some neuroprotective therapies are advocated in cases of lowered level of consciousness. With the current knowledge about neuroanatomic structures corresponding to the level and content of consciousness, the patient in coma, in vegetative state, and in minimally conscious state may benefit from some clinical measures. Therapeutic hypothermia has been used in the last 10 years in patients who have undergone cardiopulmonary arrest and, to date, is the only truly effective neuroprotective measure. Hypothermia is known to reduce the inflammatory process, decreasing the production of reactive oxygen species, excitotoxicity, apoptosis, and neuronal death. Amantadine inhibits N-methyl-D-aspartate (NMDA) channels, preventing calcium influx. In addition, amantadine is a dopaminergic agonist in the cortical regions related to attention and arousal, showing benefits in the recovery of patients who evolved to a permanent vegetative or minimally

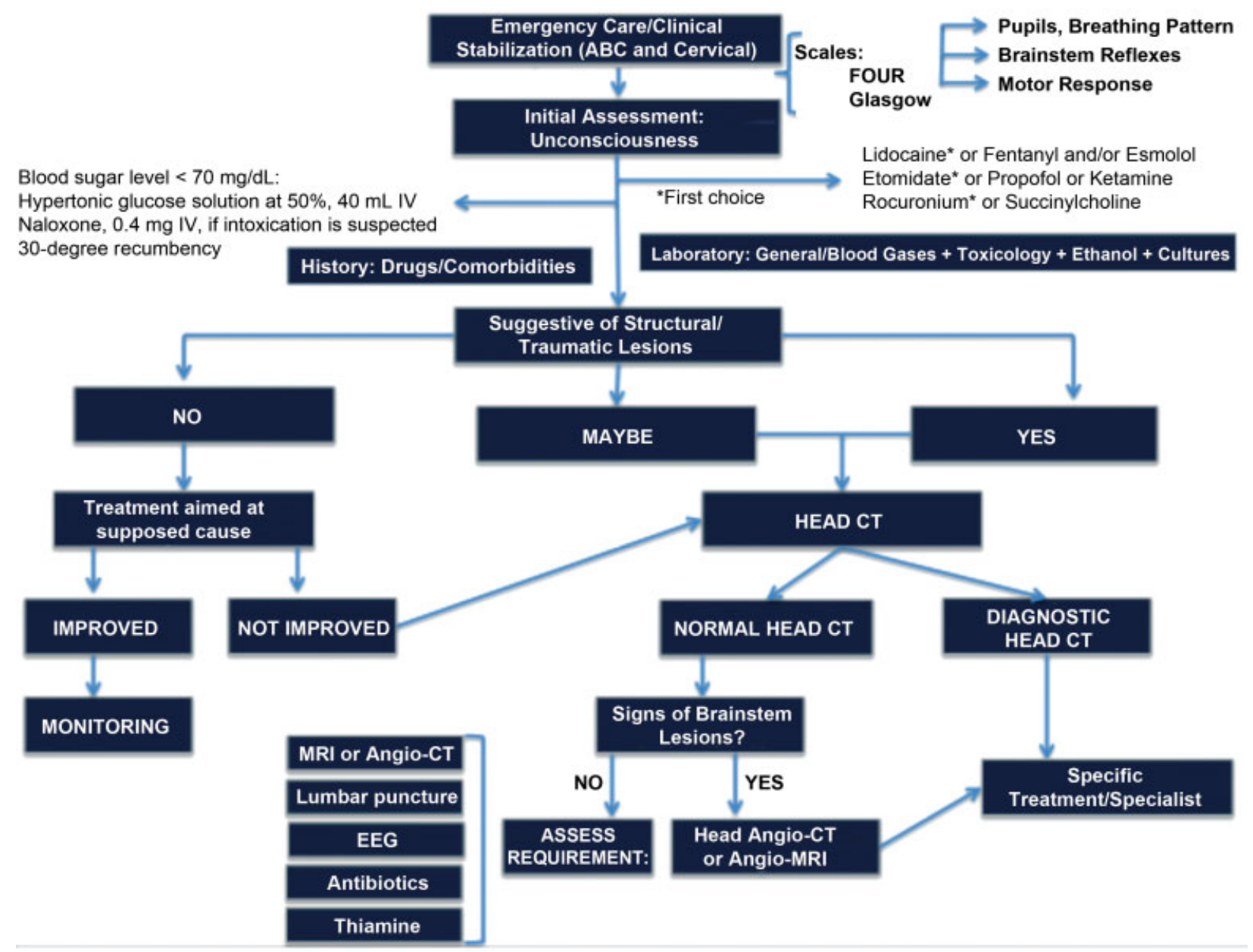

Fig. 4 Algorithm recommended for the initial care of the unconscious patient. Abbreviations: Angio-CT, angiography by computed tomography; EEG, electroencephalogram; MRI, magnetic resonance imaging. Source: adapted from Edlow et al and from Huff et al. ${ }^{1,2}$ Source: Adapted from Han et al. ${ }^{27}$ 
conscious state. Methylphenidate, an amphetamine, is a noradrenergic and dopaminergic stimulant, acting on the prefrontal cortex. Some studies show that the administration of methylphenidate to patients with severe TBI reduces the length of stay in the intensive care unit (ICU) and the hospitalization period. Modafinil (an orexin agonist), zolpidem (a GABAergic agonist) and baclofen (a GABAergic agonist) resulted in improvement of some persistent vegetative states; however, no randomized, multicenter, prospective, doubleblind study has been conducted to date, and only empirical measurements based on the individual observation of some centers are available. ${ }^{4,28}$

\section{Conclusions}

Lowering of the level of consciousness (coma status and its variants) is one of the main causes of emergency room admission. Its diverse etiological possibilities associated to the absence of clinical history, very common in this scenario, are a challenge to the emergency physician. However, initial measures should be promptly instituted according to an established protocol, based on ATLS and ACLS. Some steps recommended by the ENLS, in order to not aggravate a potentially reversible lesion, may increase the time for an investigative work on a clearer etiological definition.

\section{Conflicts of Interests}

The author has no conflicts of interests to declare.

\section{References}

1 Edlow JA, Rabinstein A, Traub SJ, Wijdicks EFM. Diagnosis of reversible causes of coma. Lancet 2014;384(9959):2064-2076

2 Huff JS, Stevens RD, Weingart SD, Smith WS. Emergency neurological life support: approach to the patient with coma. Neurocrit Care 2012;17(Suppl 1):S54-S59

3 Plum F, Posner JB. Brain death. In: Plum F, Posner JB. Diagnosis of stupor and coma. 3rd ed. Philadelphia: Davis; 1984:313-328

4 McClenathan BM, Thakor NV, Hoesch RE. Pathophysiology of acute coma and disorders of consciousness: considerations for diagnosis and management. Semin Neurol 2013;33(02):91-109

5 Monti MM, Laureys S, Owen AM. The vegetative state. BMJ 2010; 341:c3765

6 Laureys S, Celesia GG, Cohadon F, et al; European Task Force on Disorders of Consciousness. Unresponsive wakefulness syndrome: a new name for the vegetative state or apallic syndrome. BMC Med 2010;8:68

7 Laureys S, Owen AM, Schiff ND. Brain function in coma, vegetative state, and related disorders. Lancet Neurol 2004;3(09):537-546

8 Dauvilliers Y, Buguet A. Hypersomnia. Dialogues Clin Neurosci 2005;7(04):347-356
9 Stevens RD, Bhardwaj A. Approach to the comatose patient. Crit Care Med 2006;34(01):31-41

10 Moruzzi G, Magoun HW. Brain stem reticular formation and activation of the EEG. Electroencephalogr Clin Neurophysiol 1949;1(04):455-473

11 Lin JS, Anaclet C, Sergeeva OA, Haas HL. The waking brain: an update. Cell Mol Life Sci 2011;68(15):2499-2512

12 Yeo SS, Chang PH, Jang SH. The ascending reticular activating system from pontine reticular formation to the thalamus in the human brain. Front Hum Neurosci 2013;7(07):416

13 Kukkonen JP, Holmqvist T, Ammoun S, Akerman KEO. Functions of the orexinergic/hypocretinergic system. Am J Physiol Cell Physiol 2002;283(06):C1567-C1591

14 Sakurai T. The neural circuit of orexin (hypocretin): maintaining sleep and wakefulness. Nat Rev Neurosci 2007;8(03):171-181

15 Parvizi J, Damasio AR. Neuroanatomical correlates of brainstem coma. Brain 2003;126(Pt 7):1524-1536

16 Fuller PM, Sherman D, Pedersen NP, Saper CB, Lu J. Reassessment of the structural basis of the ascending arousal system. J Comp Neurol 2011;519(05):933-956

17 Smith WS, Weingart S. Emergency Neurological Life Support (ENLS): what to do in the first hour of a neurological emergency. Neurocrit Care 2012;17(Suppl 1):S1-S3

18 Teasdale G, Jennett B. Assessment of coma and impaired consciousness. A practical scale. Lancet 1974;2(7872):81-84

19 Wijdicks EFM, Bamlet WR, Maramattom BV, Manno EM, McClelland RL. Validation of a new coma scale: The FOUR score. Ann Neurol 2005;58(04):585-593

20 Davis DP, Idris AH, Sise MJ, et al. Early ventilation and outcome in patients with moderate to severe traumatic brain injury. Crit Care Med 2006;34(04):1202-1208

21 Reynolds SF, Heffner J. Airway management of the critically ill patient: rapid-sequence intubation. Chest 2005;127(04): 1397-1412

22 Seder DB, Riker RR, Jagoda A, Smith WS, Weingart SD. Emergency neurological life support: airway, ventilation, and sedation. Neurocrit Care 2012;17(Suppl 1):S4-S20

23 Dumont TM, Visioni AJ, Rughani AI, Tranmer BI, Crookes B. Inappropriate prehospital ventilation in severe traumatic brain injury increases in-hospital mortality. J Neurotrauma 2010;27 (07):1233-1241

24 Davis DP, Stern J, Sise MJ, Hoyt DB. A follow-up analysis of factors associated with head-injury mortality after paramedic rapid sequence intubation. J Trauma 2005;59(02):486-490

25 Walsh BK, Crotwell DN, Restrepo RD. Capnography/Capnometry during mechanical ventilation: 2011. Respir Care 2011;56(04): 503-509

26 Bergen JM, Smith DC. A review of etomidate for rapid sequence intubation in the emergency department. J Emerg Med 1997;15 (02):221-230

$27 \mathrm{Han} \mathrm{JH}$, Wilber ST. Altered mental status in older patients in the emergency department. Clin Geriatr Med 2013;29(01): 101-136

28 Han HS, Park J, Kim JH, Suk K. Molecular and cellular pathways as a target of therapeutic hypothermia: pharmacological aspect. Curr Neuropharmacol 2012;10(01):80-87 